\title{
Tratamiento de agua potable por filtración inducida en una laguna costera en el sur de Brasil
}

\author{
Bank filtration drinking water treatment \\ in a costal lagoon in south Brazil
}

\author{
Luis Guillermo Romero Esquivel' \\ Bruno Segalla Pizzolatti ${ }^{2}$ \\ Mauricio Luiz Sens ${ }^{3}$
}

Fecha de recepción: 4 de mayo del 2012

Fecha de aprobación: 16 de setiembre del 2012

\begin{abstract}
Romero, L; Segalla, B; Luiz, M. Tratamiento de agua potable por filtración inducida en una

laguna costera en el sur de Brasil Tecnología en Marcha. Vol. 25, Nº 4. Pág 23-32.
\end{abstract}

Químico. Escuela de Química, Tecnológico de Costa Rica. Teléfono: 2550-2229 Correo electrónico: Iromero@itcrac.cr

2 Ingeniero sanitario y ambiental. Universidad Federal de Santa Catarina, Departamento de Ingeniería Sanitaria y Ambiental. Teléfono: (0055) (48) 3721-9597. Correo electrónico: brunosegalla@hotmail.com

3 Ingeniero sanitario y ambiental. Universidad Federal de Santa Catarina, Departamento de Ingeniería Sanitaria y Ambiental.Teléfono: (0055) (48) 3721-9597. Correo electrónico: mls@ens.ufsc.br 


\section{Palabras clave}

Tratamiento de agua potable, filtración inducida, calidad de agua, laguna costera, sur de Brasil.

\section{Resumen}

La filtración inducida $(\mathrm{FI})$ consiste en obtener agua potable de pozos situados en acuíferos de aluvión u otro tipo de depósitos no consolidados conectados hidráulicamente con una fuente de agua superficial. La posibilidad de aplicar esta técnica en las riberas de la laguna Lagoa do Peri, Brasil, se evaluó a nivel piloto.

Por medio de observación y de análisis granulométricos se determinó que el fondo de la laguna y el acuífero aledaño presentan una textura arenosa. Además, ensayos de permeámetro de carga constante, de tubo de carga variable y de bombeo, mostraron que la conductividad hidráulica en las mismas zonas se encuentra cercana a $10^{-4} \mathrm{~m} / \mathrm{s}$, misma magnitud encontrada en otras latitudes donde la $\mathrm{FI}$ se aplica con éxito.

El agua captada en un pozo a 20 m de la Lagoa do Peri presentó valores de turbidez y color aparente acordes con los patrones de calidad locales. Se observó un aumento en la dureza y la alcalinidad, atribuido a la erosión de los materiales del subsuelo, sin llegar a superar lo estipulado en la legislación.

Finalmente, el agua producida por la Fl mostró ser de mejor calidad en términos de turbidez y color aparente que el agua de la laguna tratada por filtración directa en una estación de tratamiento (ETA) ubicada en el lugar. El agua producida por la FI presentó condiciones anóxicas que harían necesario el postratamiento por aireación y filtración, proceso en el cual se podría aprovechar la infraestructura de la ETA existente.

\section{Key words}

Drinking water treatment, bank filtration, water quality, coastal lagoon, South Brazil.

\section{Abstract}

Bank filtration (BF) consists in obtaining drinking water from wells in alluvial aquifers or other unconsolidated deposits hydraulically connected with a surface water source. The possibility of applying this technique was evaluated in a pilot scale on the banks of the Lagoa do Peri lagoon, Brazil.

Observation and grain size analysis showed that the bottom of the lagoon and the adjacent aquifer have sandy texture. In addition, tests of constant head permeameter, standpipe falling head and a pumping test, showed that the hydraulic conductivity in the same areas is close to $10^{-4} \mathrm{~m} / \mathrm{s}$, same magnitude found in other places where the BF is applied successful.

The water from a well at 20 meters from the Lagoa do Peri showed levels of turbidity and apparent color according to the local quality standards. It was observed an increase in hardness and alkalinity, attributed to erosion of subsurface materials, without actually exceed the provisions of the legislation.

Finally, the water produced by BF was found to be of better quality in terms of turbidity and apparent color than the lagoon water treated by direct filtration in a waterworks located on the site. The water produced by BF showed anoxic conditions that would require the post treatment by aeration and filtration, to do that, the existing infrastructure of the waterworks would be useful. 


\section{Introducción}

Las principales presiones sobre la producción de agua potable son el crecimiento demográfico y el aumento en el ingreso per cápita asociados al aumento del consumo doméstico, el requerimiento agrícola y la producción energética e industrial (World Water Assesment Programme, 2009).

Mientras tanto, las principales fuentes de agua están limitadas a las de origen superficial y subterráneo. Las primeras son muy susceptibles a la contaminación y las otras sufren por los altos costos del bombeo y principalmente la sobreexplotación. Lo anterior ha creado la necesidad de encontrar nuevas fuentes de agua de buena calidad.

Una alternativa todavía poco explorada en muchos países es la extracción de agua de acuíferos aluviales o formados por materiales no consolidados, conectados hidráulicamente a una fuente de agua superficial. Durante el bombeo en pozos cercanos a ríos y lagos ubicados en ese tipo de formaciones, el agua superficial es inducida a infiltrar por el fondo del lecho del río/lago y migrar por el acuífero hasta alcanzar los pozos (Grischek \& Ray, 2009). Esta técnica se conoce como filtración inducida $(\mathrm{Fl})$.

Durante el recorrido del agua superficial hasta el pozo, la calidad del agua mejora, entre otros, en turbidez, materia orgánica, precursores de subproductos de desinfección, bacterias, microcontaminantes y actividad mutagénica (Schubert, J., 2006).

Sens et al. (2006) atribuyen a la FI la capacidad de remover pesticidas, productos farmacéuticos, disruptores endocrinos, virus, parásitos, fitoplancton y toxinas de algas. La FI también puede remover compuestos olorosos de origen industrial como mentol, limoneno e hidrocarburos aromáticos como benceno y tolueno (Juttner, 1995). Además, presenta la capacidad de compensar variaciones de temperatura y cargas de contaminación repentina (Schubert, 2006; Hiscock \& Grischek, 2002; Kuehn \& Mueller, 2000). En relación con los costos de operación, la Fl presenta una reducción en el uso de productos químicos como coagulantes y desinfectantes y consecuentemente menor demanda de mano de obra (Ray et al. 2002).

Durante el recorrido del agua hasta el pozo, las características del agua cambian debido a procesos de filtración física, degradación microbiana, intercambio iónico, precipitación, sorción, dispersión de los componentes químicos del agua superficial en el acuífero y posterior dilución con el agua subterránea local ( Ray et al. 2003).

La eficiencia de la FI depende de la hidrogeología del acuífero, de la hidrología y morfología del cuerpo de agua, de la composición del fondo del río/lago, tiempo/distancia de recorrido hasta los pozos y de la temperatura del agua superficial y subterránea.

La Fl se ha aplicado con éxito en Europa durante más de 100 años (Ray et al., 2002) y en Estados Unidos a partir de la segunda mitad del siglo $X X$ (Ray et al., 2003). Estudios recientes indican su aplicación en India y Egipto (Shamrukh \& AbdelWahab, 2008 \& Dash et al. 2007). Sens et al. (2006) iniciaron algunos estudios en la laguna Lagoa do Peri (en adelante referida como Lagoa) en el estado de Santa Catarina, Brasil.

Esta es una laguna costera de agua dulce que presenta alto contenido de fitoplancton durante todo el año. El agua de la Lagoa tratada por filtración directa se utiliza para el abastecimiento de agua potable a cerca de 100000 personas. Debido al alto contenido de fitoplancton ( $10^{5}-10^{6}$ células $/ \mathrm{mL}$ ), los filtros de la estación de tratamiento se deben lavar periódicamente, ocasionando pérdidas por el uso de mano de obra y agua previamente tratada.

El objetivo del presente trabajo es estudiar las condiciones hidrogeológicas de la Lagoa do Peri y evaluar mediante un sistema piloto de $\mathrm{Fl}$ el potencial de dicha técnica. Además, se efectuó una comparación entre la calidad del agua obtenida por Fl y la producida por filtración directa.

\section{Descripción del lugar de estudio}

La Lagoa do Peri se encuentra en la Isla de Santa Catarina, estado de Santa Catarina, al sur de Brasil (figura I). La cuenca de la Lagoa forma parte del Parque Municipal Lagoa do Peri desde la década de 1980, por lo que las principales actividades en la región son el turismo ecológico y recreativo. No obstante, desde el 2000, el agua de la Lagoa se utiliza como fuente de consumo para la región Sur de la isla.

El clima de la región es del tipo subtropical, con una temperatura media de $24,3{ }^{\circ} \mathrm{C}$ en el verano y 16,4 ${ }^{\circ} \mathrm{C}$ en el invierno.

La precipitación anual media es de alrededor de $1519 \mathrm{~mm}$, siendo mayor durante la primavera y 
el verano (de octubre a marzo) (Mondardo, 2004 \& Simonassi, 200I). De manera similar, los vientos desde los cuadrantes N-NE y S-SE presentes todo el año aumentan en ese mismo periodo (Hennemann \& Petruccio, 201 I).

La Lagoa está rodeada al oeste, norte y sur por varias colinas y limita al este con una pequeña franja de terreno que la separa del mar (figural). La vegetación en las colinas es del tipo "mata atlántica", formada por árboles de tamaño medio y arbustos. En la región este la vegetación es del tipo restinga.

La cuenca donde se encuentra la Lagoa comprende alrededor de $20 \mathrm{~km}^{2}$. La Lagoa tiene un área superficial de $5,2 \mathrm{~km}^{2}$ y se encuentra aproximadamente a $3 \mathrm{~m}$ sobre el nivel del mar, con el canal Sangradouro sirviendo como salida al mar (figural) (Mondardo, 2004 \& Simonassi 200 I).

La geología alrededor de la Lagoa es del tipo granito (N-NE, W, SW, S y SE), reolito (SE) y predominan los materiales arenosos del tipo marino eólico en la planicie costera (Oliveira, 2002). Según Simonassi (200 I), el fondo de la Lagoa presenta dos tipos de sedimentos claramente separados: orgánicos en la parte sur oeste e inorgánicos en la región este.

El primer tipo de sedimentos presenta materia orgánica superior al 10\% (el promedio de 20 muestras fue de 33,4\%) y una fracción mineral de limo y arcilla. Este tipo de sedimento tiene su origen en la erosión del material cristalino y la vegetación alrededor de la Lagoa. Los sedimentos inorgánicos al este de la Lagoa reflejan los materiales arenosos de la franja costera mencionada anteriormente.

\section{Materiales y métodos}

\section{Sistema de filtración inducida y estación} de tratamiento para filtración directa

El sistema de infiltración inducida se construyó durante el mes de enero del 20II en la parte este de la Lagoa, al norte de la salida al canal Sangradouro. Se utilizaron piezómetros de $50 \mathrm{~mm}$ de diámetro para medir el nivel del agua a $8 \mathrm{~m}$, 20 m, 40 m y 57 m (OWI, OW2, OW3 y OW5) de distancia desde el borde de la Lagoa.

Se perforó un piezómetro de $100 \mathrm{~mm}$ de diámetro a $55 \mathrm{~m}$ de la orilla (OW4) (figura 2). Todos los piezómetros llegaron hasta una profundidad de aproximadamente $12 \mathrm{~m}$. La zona de ranuras de los piezómetros se ubicó entre los 10 y 12 m de profundidad.

Todos se construyeron siguiendo la norma de la Asociación Brasilera de Normas Técnicas (ABNT) "Poços de monitoramento de águas subterrâneas em aqüíferos granulares - Parte I: Projeto e construção" ABNT |5495-|:2007 (ABNT, 2007). E desarrollo de los pozos/piezómetros se basó en el procedimiento de surging y overpumping descritos en la norma ASTM D 552I - 05 (ASTM, 2005).

Desde el 2000, el agua de la Lagoa se trata en una estación de tratamiento de agua por filtración directa (ETA) (figura I). En esta, el agua captada en la fuente pasa por las etapas de adición de policloruro de aluminio como coagulante, mezcla rápida, filtración y desinfección.

La filtración se realiza en cinco filtros con una capa superficial de $90 \mathrm{~cm}$ de antracita y una capa

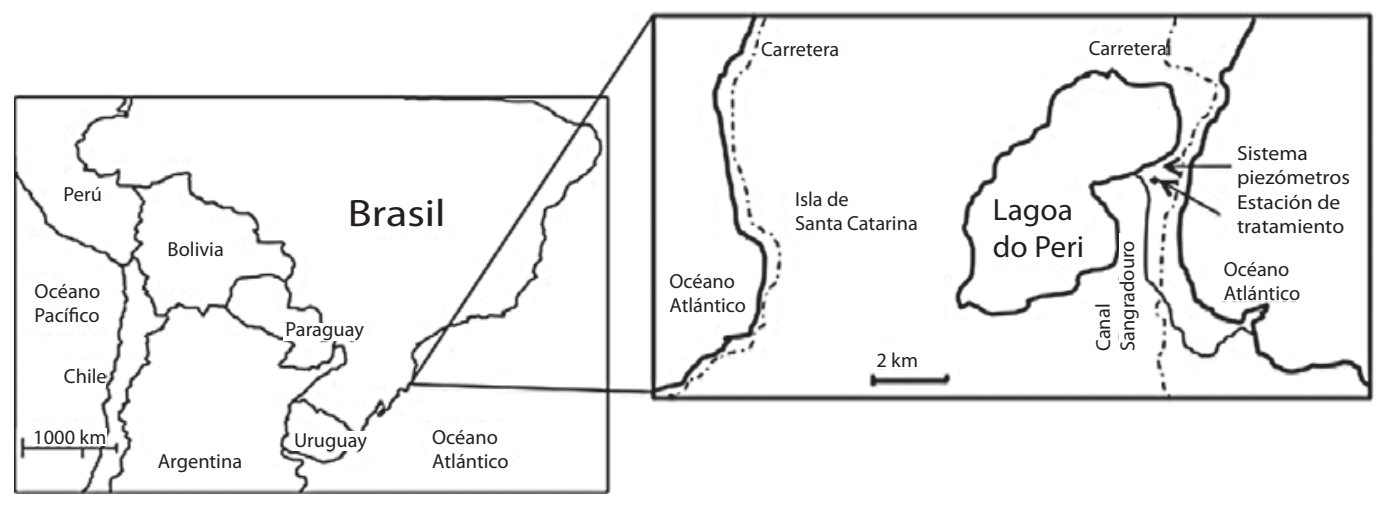

Figura I. Ubicación de la Lagoa do Peri y el lugar de estudio. 


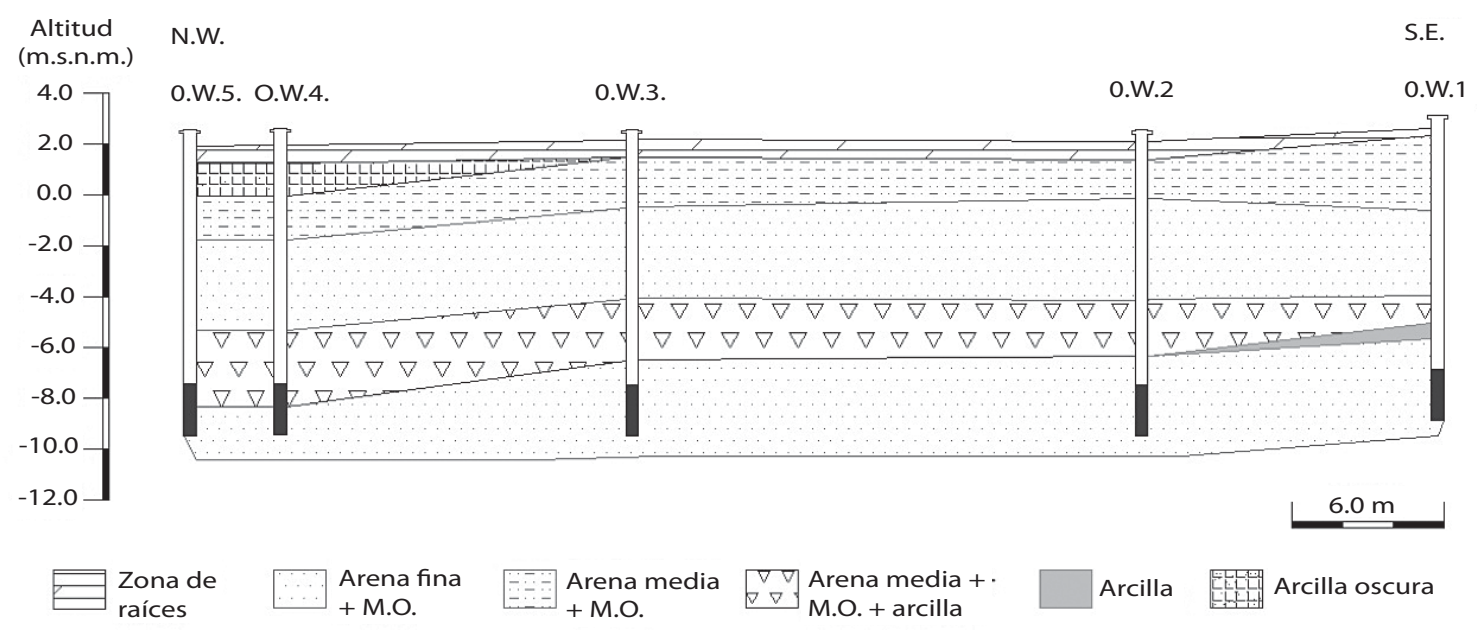

Figura 2. Perfil de los piezómetros construidos.

inferior de $30 \mathrm{~cm}$ de arena. Los filtros deben ser lavados regularmente debido al alto contenido de fitoplancton en el agua cruda.

\section{Ensayos de conductividad \\ hidráulica y granulometría}

La conductividad hidráulica fue determinada en los primeros $20 \mathrm{~cm}$ del lecho de la Lagoa, en la región de $60 \mathrm{~m}$ por $60 \mathrm{~m}$ al norte de la salida al canal Sangradouro. Los métodos utilizados fueron el de permeámetro de carga constante para muestras no deformadas y el de tubo de carga variable según los métodos descritos por Klute y Dirksen (1986) y Chen (2000) respectivamente.

En la región de los piezómetros se hizo un ensayo de bombeo para determinar la conductividad hidráulica en el acuífero. El agua del pozo OW4 fue extraída a razón de I,4 $\mathrm{m}^{3} / \mathrm{h}$, hasta alcanzar un nivel constante en este y en el piezómetro de observación OW2 por dos horas. El análisis de los datos se realizó utilizando el software Aquifer Test 3.5 (Waterloo Hydrogeologic, Inc.).

Se monitoreó el nivel del agua en la Lagoa y en los pozos/piezómetros con y sin bombeo, durante los meses de febrero y marzo del 2011. Con esa información y los datos de conductividad hidráulica, se construyó un modelo mediante el programa PWIN MODFLOW para estimar, entre otras cosas, el tiempo de recorrido del agua hasta los pozos con y sin bombeo. Los resultados del modelo serán publicados en un artículo posterior.
Los ensayos granulométricos se llevaron a cabo en un punto localizado en la misma zona, utilizando muestras recolectadas a cada $10 \mathrm{~cm}$ de profundidad hasta $50 \mathrm{~cm}$, siguiendo la norma ASTM D422-63 (ASTM, 2003).

\section{Métodos analíticos y muestreos}

El bombeo continuo de agua a razón de $\approx 35 \mathrm{~m} 3 / \mathrm{d}$ se inició en el pozo OW4 en el mes de marzo del 201 I. Posteriormente y con base en los resultados del modelo, en abril del mismo año se transfirió la bomba a $20 \mathrm{~m}$ de la Lagoa (OW2), manteniendo el mismo flujo para garantizar un menor tiempo de recorrido del agua hasta la captación.

Las actividades de muestreo de agua cruda de la Lagoa, en el pozo OW2 y en la ETA después de la etapa de filtración, se iniciaron en el mes de mayo y terminaron al final de julio del 201। (cuatro muestreos en total). Mediante el uso de una sonda multiparámetros, modelo MP 20 marca QED Environmental Systems (Michigan, USA), se midieron el $\mathrm{pH}$, el oxígeno disuelto, el porcentaje de saturación de oxígeno, la temperatura, la conductividad y el potencial redox. Esta sonda posee una célula de flujo que evita el contacto con la atmósfera al momento de realizar el análisis del agua subterránea. La turbidez y el color aparente se determinaron con equipos marca Hach modelos $2100 P$ y DR 2010 respectivamente.

Hierro (II), manganeso (II) y sulfuro de hidrógeno se determinaron utilizando un espectrofotómetro 2010 
Hach según los métodos recomendados (Hach 2000) e inmediatamente después de la colecta. Los iones nitrato y cloruro se determinaron mediante un cromatógrafo iónico DIONEX 100, siguiendo métodos estandarizados (APHA, AWWA, WEF, 2005). La alcalinidad, la dureza total, la dureza calcio y la dureza magnesio se analizaron mediante titulación y según métodos estándar (APHA, AWWA, WEF, 2005). Los métodos de muestreo, preservación y manipulación de las muestras se realizaron siguiendo las recomendaciones del Standard Methods (APHA, AWWA, WEF, 2005).

\section{Resultados y discusión}

\section{Conductividad hidráulica y análisis granulométrico}

El éxito de la $\mathrm{Fl}$ depende del grado de conexión hidráulica entre el fondo del reservorio de agua y el acuífero adyacente. La granulometría y la conductividad hidráulica en ambas zonas son buenos indicadores del grado de conexión hidráulica.

Según los resultados de los análisis granulométricos realizados, los primeros $50 \mathrm{~cm}$ del lecho de la Lagoa en la zona estudiada consisten en aproximadamente $13 \%$ de arena media (0,25-0,5 mm), 83\% de arena fina $(0,125-0,25 \mathrm{~mm}), 3,5 \%$ de arena muy fina $(0,063-0,125 \mathrm{~mm}$ ) y menos de 0,02\% de finos (limo y arcilla, $<0,063 \mathrm{~mm}$ ).

Estos resultados indican un material de textura arenosa con un coeficiente de uniformidad $\left(\mathrm{d}_{60}\right)$ $\mathrm{d}_{20}$ ) aproximado de 1,4, característico de materiales muy uniformes. Lo cual no es muy ventajoso para la aplicación de la $\mathrm{Fl}$ por la posible colmatación del fondo de la Lagoa. Sin embargo, debido a la presencia de olas generadas por los vientos y a la baja profundidad de la Lagoa, es de esperar la autolimpieza en la zona de infiltración.

Por otra parte, no fue posible determinar la granulometría en la región de los pozos, debido a que la técnica de chorro en la construcción de los pozos/piezómetros no permite tomar una muestra de material no deformada. No obstante, mediante la observación visual y el tacto, se determinó la presencia principalmente de material arenoso con materia orgánica y esporádicamente regiones con arcilla (figura2). Sens et al. (2006) observaron una formación semejante con una profundidad de acuífero cercana a los 20 m. Este tipo de formación en el subsuelo favorece la conexión hidráulica con la Lagoa.

El fondo de la margen este de la Lagoa, en la región de los pozos y piezómetros, mostró valores medios de conductividad hidráulica cercanos a $2,2 * 10^{-4} \mathrm{~m} / \mathrm{s}$ por los métodos de tubo con carga variable y permeámetro constante (cuadro I). La conductividad, según el test de bombeo realizado en la región de los pozos y piezómetros en el acuífero, fue de $1.5^{*} 10^{-4} \mathrm{~m} / \mathrm{s}$, calculado por el método de Theis. Ambos resultados son similares a los encontrados en acuíferos de aluvión con conductividad hidráulica entre $10^{-2}$ y $10^{-4} \mathrm{~m} / \mathrm{s}$ en otras latitudes donde la $\mathrm{Fl}$ se ha aplicado con éxito (Grischek et al., 2007).

Cuadro I. Conductividad hidráulica en el fondo de la Lagoa en la región del sistema de FI

\begin{tabular}{|c|c|c|}
\hline Método & $\begin{array}{c}\text { Tubo con } \\
\text { carga variable }\end{array}$ & $\begin{array}{c}\text { Permeámetro de } \\
\text { carga constante }\end{array}$ \\
\hline Promedio & $2.2 * 10^{-4}$ & $2.1 * 10^{-4}$ \\
\hline Mínimo & $3.0^{*} 10^{-5}$ & $4.1 * 10^{-5}$ \\
\hline Máximo & $8.7 * 10^{-4}$ & $4.4^{*} 10^{-4}$ \\
\hline Total de mediciones & 10 & 16 \\
\hline
\end{tabular}

Utilizando los datos de conductividad hidráulica y las mediciones de nivel freático, se realizó un modelo del comportamiento del agua subterránea de la región (más detalles sobre el modelo serán publicados posteriormente). Con este modelo fue posible determinar que el agua de la Lagoa infiltra de forma natural en dirección al sistema de piezómetros.

En condiciones naturales (sin bombear), el tiempo mínimo de recorrido del agua, desde el fondo de la Lagoa hasta donde se inician las ranuras del pozo (OW2) situadas a 9,5 $\mathrm{m}$ de profundidad del pozo, se estimó en $190 \mathrm{~d}$. Al aplicar bombeo suficiente para producir $\approx 30 \mathrm{~m}^{3} / \mathrm{d}$ de agua, el tiempo mínimo de recorrido del agua estimado fue de al menos $80 \mathrm{~d}$ hasta el mismo punto.

Es de esperar que ese tiempo de contacto garantice la calidad microbiológica del agua captada en el pozo. Según Dash et al. (2008), en Alemania comúnmente se recomienda un tiempo de $50 \mathrm{~d}$ para eliminar las bacterias y generar una zona de 
protección sin contaminación microbiana. Incluso, los mismos autores reportaron reducciones de coliformes totales y fecales de 5,2 log y 4,2 log en un tiempo estimado de II a 19 d (calculado utilizando la ley de Darcy) en un sistema de Fl en el Lago Nainital, India.

\section{Calidad del agua}

Los resultados de los análisis realizados durante el periodo de estudio se presentan en el cuadro 2. El agua cruda de la Lagoa solamente presentó valores superiores a los establecidos por la legislación local en los parámetros turbidez y color aparente (cuadro 2).
El agua producida por $\mathrm{Fl}$ siempre estuvo muy por debajo de lo estipulado en la legislación para ambos parámetros. El valor de turbidez obtenido es semejante al resultado registrado en India, Egipto y Estados Unidos (Dash et al., 2007; Shamrukh \& Abdel-Wahab, 2008; Wang, 2003). La reducción en la turbidez generalmente se relaciona con una reducción en materiales suspendidos, que a su vez puede relacionarse con una reducción de la carga microbiana en el agua (Ray et al., 2002).

En este caso, es un buen indicador de la reducción del fitoplancton, que es el principal problema en el agua de la Lagoa. La disminución en el color aparente del agua después de la infiltración indica una reducción en el contenido de materia orgánica

\section{Cuadro 2. Comparación entre el agua cruda, el agua por filtración inducida, el agua de la estación de tratamiento y la legislación brasileña}

\begin{tabular}{|c|c|c|c|c|}
\hline Parámetros & Agua de la laguna & Filtración inducida & Filtración directa & $\begin{array}{c}\text { PORTARIA No- } 2.914 \\
(\mathrm{MS}, 20 \mathrm{II})\end{array}$ \\
\hline $\begin{array}{l}\text { Turbidez } \\
\text { (NTU) }\end{array}$ & $6,70^{a} \pm 0,89^{b}$ & $0,19 \pm 0,07$ & $2,69 \pm 0,01$ & $0,5^{c} / 1,0 \mathrm{~d} / 5^{\mathrm{e}}$ \\
\hline $\begin{array}{l}\text { Color aparente } \\
\qquad(\mathrm{uH})\end{array}$ & $90 \pm 3$ & $6 \pm 3$ & $39 \pm 6$ & 15 \\
\hline $\begin{array}{l}\text { Temperatura } \\
\left({ }^{\circ} \mathrm{C}\right)\end{array}$ & $20,67 \pm 3,95$ & $22,35 \pm 0,18$ & $19,12 \pm 3,57$ & \\
\hline Conductividad $(\mu \mathrm{S} / \mathrm{cm})$ & $64 \pm 4$ & $235 \pm 10$ & $66 \pm 2$ & \\
\hline $\mathrm{pH}$ & $7,38 \pm 0,64$ & $7,86 \pm 0,13$ & $5,97 \pm 0,06$ & \\
\hline $\begin{array}{l}\text { Alcalinidad } \\
\text { (mg/L) }\end{array}$ & $7,4 \pm 0,27$ & $105 \pm 5$ & $6,7 \pm 3,8$ & \\
\hline $\begin{array}{l}\text { Dureza total } \\
\qquad(\mathrm{mg} / \mathrm{L})\end{array}$ & ||$\pm 0,8$ & $96 \pm 8$ & $19 \pm 12$ & 500 \\
\hline $\begin{array}{l}\text { Dureza Calcio } \\
\qquad(\mathrm{mg} / \mathrm{L})\end{array}$ & $7,8 \pm 3,1$ & $85 \pm 4,7$ & $8,8 \pm 2,8$ & \\
\hline Dureza Magnesio (mg/L) & $4,2 \pm 2,6$ & $10 \pm 10$ & $12 \pm 12$ & \\
\hline $\begin{array}{c}\text { Cloruro } \\
(\mathrm{mg} / \mathrm{L})\end{array}$ & $|1,88 \pm 0,7|$ & $|4,7| \pm 0,32$ & $11,98 \pm 0,72$ & 250 \\
\hline $\mathrm{ORP}(\mathrm{mV})$ & $52 \pm 32$ & $-307 \pm 6$ & $168 \pm 12$ & \\
\hline Oxígeno disuelto (mg/L) & $8,64 \pm 0,68$ & $0,22 \pm 0,23$ & $8,82 \pm 0,67$ & \\
\hline $\begin{array}{l}\text { Nitrato } \\
(\mathrm{mg} / \mathrm{L})\end{array}$ & N.D. & N.D. & N.D. & 10 \\
\hline $\begin{array}{l}\text { Hierro (II) } \\
\quad(\mathrm{mg} / \mathrm{L})\end{array}$ & N.A. & $0,010 \pm 0,009$ & N.A. & \\
\hline Manganeso (II) (mg/L) & N.A. & $0,094 \pm 0.036$ & N.A. & \\
\hline Sulfuro de hidrógeno $(\mathrm{mg} / \mathrm{L})$ & N.A. & $0,018 \pm 0,020$ & N.A. & 0,1 \\
\hline
\end{tabular}

aPromedio. b Desviación estándar. N.D. No detectado. N.A. No analizado

Límite de detección de nitrato: 0,018 mg/L. 
responsable del mismo. La producción de agua con bajo contenido de materia orgánica es de vital importancia para evitar el recrecimiento bacteriano en los sistemas de distribución y reducir la formación de trialometanos después de la desinfección con cloro (Kuehn \& Mueller, 2000).

La reducción de la materia orgánica durante la FI se debe principalmente a procesos de biodegradación y en menor grado a adsorción (Grünheid, Amy \& Jekel, 2005). Durante la biodegradación, los microorganismos consumen primeramente la materia orgánica utilizando el oxígeno disuelto en el agua como aceptor de electrones.

Una vez que se reduce la disponibilidad de oxígeno, los microorganismos continúan utilizando otros aceptores de electrones tales como: nitrato, hierro (III), manganeso (III), sulfato y materia orgánica. Los resultados en la Lagoa muestran que durante el recorrido del agua hasta el pozo, todo el oxígeno es consumido, generando condiciones anóxicas, lo cual es corroborado por el bajo potencial de óxido reducción (ORP) (cuadro 2).

El agua de la Lagoa presenta bajas concentraciones de ión nitrato y los datos indican que el generado durante el proceso de biodegradación es posteriormente consumido en el paso por el subsuelo. Los resultados indican también muy bajas concentraciones de hierro (II), manganeso (II) y sulfuro de hidrógeno (subproductos del consumo de los otros aceptores de hidrógeno).

Sin embargo, para garantizar agua de buena calidad, es necesaria una etapa de postratamiento consistente en aireación y postfiltración en arena. Este tipo de sistema se aplica ampliamente en sistemas de tratamiento de agua en Holanda como postratamiento de agua producida por infiltración inducida (de Vet et al. 20।0).

Durante el paso del agua por el subsuelo se dan procesos de erosión o disolución de los materiales que conforman el acuífero. Lo anterior se ve reflejado en un aumento en la conductividad, la dureza total (mayoritariamente dureza calcio) y la alcalinidad conjuntamente con el pH. Ese tipo de comportamiento se ha observado en un local de infiltración inducida en un lago en India (Dash et al., 2007). Es de esperar que un aumento en el bombeo genere una disminución en las concentraciones de los parámetros mencionados.
Finalmente, la concentración del ión cloruro en el agua del pozo indica la ausencia de inclusión de la cuña salina en el agua producida. Además, la semejanza con la concentración en el agua de la Lagoa apoya los resultados del modelo que según los cuales el agua en el pozo proviene principalmente de la laguna.

\section{Comparación entre la filtración inducida y la filtración directa}

El agua de la Lagoa tratada por filtración directa fue igualmente monitoreada durante el periodo de estudio. Los datos de del cuadro 2 muestran una remoción de entre el $57 \%$ y el $60 \%$ en los parámetros color aparente y turbidez en este sistema. Mientras tanto, la reducción utilizando Fl fue superior al $90 \%$ en ambos parámetros.

Los restantes parámetros, como alcalinidad, dureza, oxígeno disuelto y ion cloruro, reflejaron las características del agua cruda. Las diferencias anteriores se deben principalmente a que en el sistema de filtración directa los procesos de remoción son básicamente coagulación/floculación y filtración mecánica.

En la Fl existen procesos de filtración, adsorción, precipitación y biodegradación, entre otros. Sin embargo, conforme a lo reportado por Dash et al. (2007), al comparar un sistema de Fl con un sistema de filtración rápida en India, la diferencia puede deberse principalmente a diferencias en la velocidad de la filtración, el tiempo de detención del agua y a características granulométricas del material filtrante.

En la actualidad, el sistema de filtración directa utilizado en la Lagoa necesita de productos químicos (coagulantes) para operar y la limpieza de los filtros se realiza a diario.

Contrariamente, en el caso de adaptar un sistema de Fl, sería innecesario el uso de productos químicos y la limpieza de la zona de infiltración en el fondo de la Lagoa se haría de forma natural. Una posible desventaja de la Fl puede derivarse de las características anóxicas del agua obtenida, generando la necesidad de una etapa posterior de aireación y filtración. Esta siguiente etapa de tratamiento podría realizarse aprovechando los sistemas existentes en la ETA y no necesitaría de la adición de productos químicos y las carreras de filtración (tiempo de filtración sin necesidad de lavar el filtro) serían prolongadas. 


\section{Conclusiones}

En la region estudiada, el fondo de la Lagoa do Peri y el acuífero adyacente a la misma presentan una granulometría arenosa que garantiza la conexión hidráulica entre el agua superficial y el acuifero. El agua producida por $\mathrm{Fl}$ presenta características acordes con la legislación local en cuanto a los parámetros analizados.

Parámetros que fueron incluso de superior calidad al agua producida por un sistema de filtración directa ubicado en el local. Los posibles problemas derivados de las características anóxicas (hierro, menganeso, por ejemplo) del agua captada por $\mathrm{FI}$ se pueden superar mediante posteriores etapas de aireación y filtración, para lo cual se podría aprovechar la infraestructura de filtración existente en el local.

\section{Bibliografía}

ABNT (2007). Poços de monitoramento de águas subterrâneas em aqǘferos granulares. Parte I: Projeto e construção" ABNT |5495-|:2007. Asociación Brasilera de Normas Técnicas.

APHA, AWWA, WEF (2005). Standard methods for the examination of water and wastewater. 21 ed. Washington, DC: American Public Health Association.

ASTM (2003). Standard Test Method for Particle-Size Analysis of Soils ASTM D422-63. Pensylvannia, ASTM International.

ASTM (2005). Standard Guide for Development of Ground-Water Monitoring Wells in Granular Aquifers ASTM D 5521 - 05. Pensylvannia, ASTM International.

Chen, X. (2000). Measurement of streambed hydraulic conductivity and its anisotropy. Environmental Geology, 39(I2): 1317-1324.

Dash, R.R.; Mehrotra, l.; Kumar, P. \& Grischek, T. (2008). Lake bank filtration at Nainital, India: water-quality evaluation. Hydrogeology Journal, 16(6): 1089-1099. doi: I 0. I 007/s I 0040-008-0295-0

de Vet,W.W.J. M.; van Genuchten, C.C.A.; van Loosdrecht, M.C.M. \& van Dijk, J.C. (20 I0). Water quality and treatment of river bank filtrate. Drinking Water Engineering and Science 3(I): 79-90. doi: 10.5 194/dwes-3-79-20I0

Grischek,T.; Schubert, J.; |asperse, J.L.; Stowe, S.M. \& Collins, M.R. (2007). What is an appropriate site for RBF? En: Fox, P. (ed.). Management of Aquifer Recharge for Sustainability (Vol. 16, pp. 466-474). Phoenix, Arizona: Acacia Publishing Incorporated.

Grischek, T. \& Ray, C. (2009). Bank filtration as managed surface-groundwater interaction. International Journal of Water 5(2): 125-139. Inderscience.
Obtenido desde http://inderscience.metapress.com/ index/I w | 4q I 277 | 295676.pdf

Grünheid, S.; Amy, G. \& Jekel, M. (2005). Removal of bulk dissolved organic carbon (DOC) and trace organic compounds by bank filtration and artificial recharge. Water research, 39(14): 3219-28. doi:10.1016/j. watres.2005.05.030

Hach (2000). Hach DR/20IO Spectrofotometer procedures manual. USA: Hach Company, 872 p.

Hennemann, M.C. \& Petruccio, M.M. (20I I). Spatial and temporal dynamic of trophic relevant parameters in a subtropical coastal lagoon in Brazil. Environmental Monitoring and Assessment, I81:347-36 I doi: 10. I007/ s|066|-0| 0-1833-5

Hiscock, K.M. \& Grischek, T. (2002). Attenuation of Groundwater Pollution by Bank Filtration. Journal of Hydrology, 266: 139-144.

Jüttner, F. (1995). Elimination of terpenoid odorous compounds by slow sand and river bank filtration of the Ruhr River, Germany. Water Science and Technology, $31(11): 211-217$.

Klute, A. \& Dirksen, C. (1986). Hydraulic Conductivity and Diffusivity: Laboratory Methods. En: Klute, A. (ed.). Methods of soil analysis. Part I: physical and mineralogical methods. 2 ed., pp. 687-732. Madison, Wisconsin: American Society of Agronomy, Inc. Soil Science Society of America, Inc.

Kuehn, W. \& Mueller, U. (2000). Riverbank filtration an overview. Journal AWWA 92(I2): 60-69.

Mondardo, R. (2004). Influência da Pré-oxidação na Tratabilidade das Águas Via Filtração Direta Descendente em Manancial com elevadas Concentrações de Microalgas e Cianobactérias. Universidade Federal de Santa Catarina. Obtenido desde http://www.tede.ufsc.br/teses/PGEA0 I 85.pdf

Oliveira, J. (2002). Análise sedimentar em zonas costeiras: subsídio ao diagnóstico ambiental da Lagoa do PeriIlha de Santa Catarina-SC, Brasil. Universidade Federal de Santa Catarina.

Ray, C.; Grischek, T.; Schubert, J.; Wang, J. \& Speth,T. (2002). A perspective of Riverbank filtration. Journal AWWA 94(4): 149-60.

Ray, C.; Schubert, J.; Linsky, R. \& Melin, G. (2003). Introduction. En: Ray, C.; Melin, G. \& Linsky, R. (eds.). Riverbank filtration: improving source-water quality. (Pp. I - 15). Dordrecht: Kluwer Academic Publisher.

Sens, M.; Mondardo, R.; Dalssasso, R. \& Melho, L. (2006). Filtração em Margem. En: PROSAB (ed.). Contribuição ao estudo da remoção de cianobactérias e microcontaminantes orgânicos por meio de técnicas de tratamento de água para consumo humano, Capítulo 5 (Pp. 173-236). Rio de Janeiro: ABES. Obtenido desde http://www.finep.gov.br/prosab/produtos.htm

Shamrukh, M. \& Abdel-Wahab, A. (2008). Riverbank filtration for sustainable water supply: application to a large-scale facility on the Nile River. Clean Technologies and Environmental Policy 10(4): 35I-358. doi: I 0. I007/ sl0098-007-0| 43-2. 
Schubert, J. (2006). Significant of hydrologic aspects on RBF performance. En:Hubbs, S.A. (ed.). Riverbank Filtration Hydrology (Pp. I-20). Dordrecht: Springer.

Simonassi, J. (200I). Caracterização da Lagoa do Peri, através da análise de parâmetros físico-químicos e biológicos, como subsídio ao gerenciamento dos recursos hídricos da llha de Santa Catarina, SC, Brasil. Universidade Federal de Santa Catarina.
Wang, J. (2003). Riverbank filtration case study at Louisville, Kentucky. En: Ray, C.; Melin, G. \& Linsky, R. (eds.). Riverbank filtration: improving source-water quality. (Pp. I 17- 46). Dordrecht: Kluwer Academic Publisher.

World Water Assessment Programme (2009). The United Nations World Water Development Report 3: Water in a Changing World (p. 3 |8). Obtenido desde http://www. unesco.org/water/wwap/wwdr/wwdr3/ 